\section{Body-Worn Cameras Effect on Victim Reactions to Police on Interviews}

\author{
Davis $\mathbf{C R}^{*}$ \\ Department of Experimental Psychology, University of Wisconsin, USA
}

\begin{abstract}
Objectives: Determine how victims respond to interactions with officers who wear body cameras.

Methods: Using a quasi-experimental design with high degree of internal validity, we examined victim reactions to police interviews under three conditions: (a) officer does not have a body camera, (b) officer wearing camera requests permission to record interview, and (c) officer wearing camera notifies victim or witness that they are being recorded.
\end{abstract}

Results: No differences between any conditions in victim ratings of interaction with an officer. Observational data documented that, in $98 \%$ of the interactions observed in which officers wore cameras, victims did not visibly react to being recorded, even when being told that they were being filmed.

Conclusion: Most victims are not concerned about being recorded during police field interviews. The study broke new ground in using a combined SMS and phone methodology to survey victims, resulting in both a higher response rate and lower costs.

Keywords: body-worn cameras; Policing

\section{Introduction}

Along with the deployment of cameras, a body of research has quickly accumulated on the benefits and limitations of body-worn cameras, as well as on policies governing their use and their effect on public opinion of the police. Proponents of police body cameras have cited numerous benefits associated with wearing the cameras. The most obvious benefit is simply having a video recording from the officer's perspective. This allows police to capture an incident in its entirety rather than having to rely on video from bystanders, which

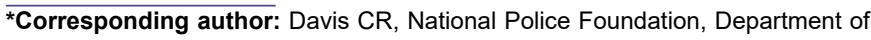
Experimental Psychology, University of Wisconsin, USA, Tel: +1 608-263-2400; E-mail: rdavis@policefoundation.org

Citation: Davis CR (2020) Body-Worn Cameras Effect on Victim Reactions to Police on Interviews. J Forensic Leg Investig Sci 6: 053.

Received: October 20, 2020; Accepted: November 13, 2020; Published: November 20, 2020

Copyright: @ 2020 Davis CR This is an open-access article distributed under the terms of the Creative Commons Attribution License, which permits unrestricted use, distribution, and reproduction in any medium, provided the original author and source are credited. often only captures the use of force and, thus, portrays the police in a negative light. Additionally, body cameras are touted for increasing professionalism and transparency and they are widely supported as a means for improving police officer accountability [1-4] argued that body cameras would decrease the number of unconstitutional searches and seizures conducted by the police. Body camera video can also serve as a valuable training tool for police officers, a point particularly emphasized by the UK Home Office [5].

Perhaps the most important benefit of deploying body-worn cameras is the potential "civilizing effect" these cameras may have on the behaviour of both officers and citizens [6] In other words, the knowledge that an incident is recorded and may be reviewed may improve the behaviour of both officers and citizens [7]. Body cameras may "both deter the police officer from reacting with excessive or unnecessary force and cool down the 'aggressive demeanor' of the suspect". This hypothesis has thus far been supported in field studies, such as the study by [8] which found that wearing cameras changed officer and civilian behaviour in positive ways based on observers' ratings. The most common measures of behaviour in police-citizen interactions are citizen complaints and use of force. The review of body camera research by [9] based on 22 studies concludes that the evidence suggests that cameras reduce the number of citizen complaints. For example, [10] conducted a randomized trial in Arlington, Texas which found that officers trained in BWCs experienced a 38\% drop in complaints between the year prior to the study and the same six months a year later, are not as positive about the effect of body cameras on use of force, where the findings of 16 studies are fairly evenly split on whether body cameras are associated with less officer use of force. Two recent randomized trials have reported contradictory results, with finding a significant reduction in use of force and citizen complaints in Las Vegas and [11] finding no significant differences on these measures attributable to wearing cameras in the District of Columbia.

Proponents of body-worn cameras also advocate for the evidentiary benefits of the cameras. In Scott v. Harris, the U.S. Supreme Court ruled that video evidence is more reliable than eyewitness testimony, so it follows that video collected from body-worn cameras has a special status in court proceedings. Indeed, prosecutors report that video evidence can be the deciding factor in whether to prosecute [12], can increase the probability of conviction, and can increase "the number of guilty pleas prior to going to trial" (IACP, 2003 as cited in Ferrell, 2013, p.16). There is evidence from a study in Renfrewshire, Scotland, which suggests that cases involving a police officer with a body camera are less likely to go to trial compared to other court cases [13]. However,[14] reported that, although cameras were associated with significantly shorter adjudication times, they had no impact on the rate of pleas. The review makes clear that, while studies to date suggest an effect of body cameras on the likelihood of court filings and convictions, the weak research designs do not allow the drawing of firm conclusions.

There is some evidence that body camera recordings may be beneficial to officers when it comes to defending against citizen 
complaints. It has been suggested that recordings may lead to quicker resolution of complaints against officers [15] discourage the filing of unfounded complaints and exonerate officers of wrong doing [16-18] Again, more research is needed to verify these claims.

\section{Concerns about body-worn cameras}

Despite the many potential benefits of body-worn cameras, there are a number of concerns associated with their use. One significant concern is that equipping police officers with body-worn cameras greatly increases the amount of electronic surveillance of the population since cameras worn by officers responding to calls for service capture not only images of suspects and victims, but also bystanders. As facial recognition software becomes ever more accurate, police agencies will be in possession of a tool for running checks on images of citizens much as they now utilize license plate readers [19]. Concerns have been expressed that body cameras may reduce officer productivity. Evidence from a study in Victoria, Canada reported that officers spent more time completing paperwork where video evidence was included [20,21] observed a reduction in subject stops (but not traffic stops) among officers wearing cameras. Other field research has found either no change in productivity or mixed results [22,23]. Another concern about body cameras is the cost. Price per camera ranges from $\$ 120-\$ 2,000$, with the average cost between $\$ 800$ and $\$ 1,200$, and larger agencies often dedicate administrative staff to body camera programs. Data storage costs can reach into the millions of dollars, depending on the number of cameras deployed and departmental policies regarding data storage [24]. Other back-end costs, such as tagging video footage, preparing video footage for use as evidence in court cases, and reviewing and redacting footage in response to Freedom of Information Act (FOIA) requests can also be substantial [25]. Still, [26] found the costs of a body camera program were offset by money saved investigating citizen complaints and performing internal investigations.

\section{Body cameras and victim and witness privacy}

One of the most prominent concern about body cameras is the potential for invasion of privacy $[27,28]$.The importance of external stakeholders for police body-worn camera diffusion. By the nature of their design, body-worn cameras are able to film inside private homes and capture highly sensitive situations. This means that body cameras are far more intrusive than police car video recorders, which can only capture events and people in public settings. Body cameras may capture victims and their families in states of distress, inebriation, confusion, or even undress-embarrassing situations that few people would want to share with the public [29]. With the introduction of body cameras, it becomes difficult to protect the privacy rights of victims and witnesses if they do not have the opportunity to determine what is recorded, what may be released to the defense, or may become public. Police body cameras in victims' homes may capture not just an interview with an individual, but ambient activity in the home at the time. Cameras may inadvertently capture confidential conversations between victims and victim advocates, or medical staff on the scene. They may capture images or audio recording of children or others present in the home who are not involved in the criminal incident. Body camera records of victim accounts of an incident can be used later to harm victims in a variety of ways. In many states, camera recordings are subject to FOIA requests; news media may acquire and publish images that may be embarrassing to victims and their families. In fact, at the February 24, 2016 International Association of
Chiefs of Police (IACP) / Office on Violence Against Women (VW) National Forum on Body Worn Cameras and Violence Against Women Impact, it was noted that several police agencies have a policy of making available all body camera recordings on their websites, with faces blurred out.

When an arrest is made and a court case ensues, prosecutors must make available at least some relevant body camera footage to defense attorneys and their clients. Viewing footage of the victim's interview with the police, with all of the attending emotions, may inflame offenders in domestic abuse cases far more than seeing the victim's statement in print on a police report. Further, when victims are in a state of trauma following a crime, their narratives may be confused, non-linear, and sometimes contradictory [30,31]. Defense attorneys may be able to challenge victims' testimony in court using their statements from video footage more effectively than they would have been able to do from victim statements in paper police reports. Finally, for victims of domestic violence especially, body camera recordings can be used in a coercive way by district attorneys bent on conducting "evidence-based" or "victimless" prosecutions in instances when victims have a change of heart about cooperating in the prosecution of their spouse of intimate partner. At the IACP/OVW conference referenced above, several attendees noted that prosecutors in their jurisdictions had used- even as a matter of policy-body camera footage in lieu of victim testimony when victims recanted or refused to testify. An even worse outcome from victims' perspectives is that body camera footage of children in a violent home could be used by prosecutors to coerce victims to testify against spouses under threat of requesting that child protective services take custody of the children.

For all of these reasons, there are serious concerns whether filming interviews with victims and witnesses - especially inside of private homes may make them less willing to talk to the police[32] and may exacerbate the emotional trauma felt by some victims (Alexander, 2014), particularly victims of rape and abuse. This potential for abuse, combined with the unprecedented invasion of privacy [33], underscores the need for a serious investment in evidence-based policy development governing the recording procedures for body-worn cameras, especially as they relate to recoding interviews with victims and witnesses [34]. Both the Police Executive Research Forum (PERF) and the IACP have developed model policies for use of police body cameras. The PERF policy argues against recording all encounters with the public, stating that such a policy could undermine privacy rights and damage the openness between police and the community. With respect to victims and witnesses, "officers should be required to obtain consent prior to recording interviews with crime victims". PERF's rationale behind this recommendation is that such a policy would be the best way to balance the significant privacy concerns associated with video recording crime victims with the need for accurate documentation. The PERF policy recommendations also state "officers should have the discretion to keep their cameras turned off during conversations with crime witnesses and members of the community who wish to report or discuss criminal activity in their neighbourhood". In contrast to the PERF model policy, the IACP model policy does not require that victims give consent to having body cameras on. Rather, it states that officers should be given a degree of discretion to discontinue recording in sensitive situations, such as when talking to a sexual assault victim or at the scene of a particularly violent crime or accident, as long as they record the reason for deactivating the recording [35]. 
According to PERF, many police departments in one-party consent states do not require officers to inform the public that they are being recorded. The PERF report indicates that many law enforcement agencies have "taken the position that officers have the right to record inside a private home, as long as they have a legal right to be there", such as with a search warrant, following consent from the resident, or responding to a call for service. Surprisingly, in a survey conducted by PERF, nearly one-third of law enforcement agencies that reported using body-worn cameras did not have a written policy in place to govern their use. Because of all of the concerns mentioned above, victims and witnesses may feel inhibited in providing information to officers wearing body cameras. In an ethnographic study, observed officer-citizen interactions became more "constrained and scripted" and "stilted and artificial" [36]. So there are real questions as to how citizens will react during encounters with officers wearing body cameras. Will they perceive officers wearing body cameras more positively because they believe that the cameras will hold officers to a higher standard of behaviour and accountability? Or, as Rowe et al. suggested, will the presence of cameras inhibit victims and make them more reluctant to talk freely with officers? A recent study provided some evidence that bears on these questions. In a randomized trial, the researchers compared citizen perceptions of routine encounters with police officers who did and who did not wear body cameras. Specifically, the citizens were asked about their perceptions of significantly better perceptions of police legitimacy, satisfaction with their interactions, and views of police professionalism. The PERF researchers did not find a difference in citizen perceptions between camera and no-camera conditions, although the study was flawed by a very low survey response rate.

Another randomized study by the Urban Institute also looked at the issue of how citizens respond to officers wearing body cameras [37] compared citizen perceptions of encounters with police officers in three conditions: officer did not wear a body camera, officer wore a body camera, and officer wore a body camera and announced to the citizen that their conversation was being recorded. A subsequent survey asked citizens to rate their perceptions of the interaction on 15 questions in the domains of officer empathy, quality of decision making, quality of treatment, and officer-provided information. The researchers found that citizen satisfaction with the police encounter was higher when officers wore a camera than when officers did not, but satisfaction was highest when the officer wore a camera and announced that their interaction was being recorded. A very recent quasi-experiment in Turkey found that just the presence of body cameras with an announcement that citizens in traffic stops were being recorded had a strong effect on how they perceived the encounter [38] reported that, compared to a condition where officers did not wear cameras, citizens stopped by officers wearing cameras reported enhanced perceptions of procedural justice during the encounter and enhanced perceptions of the legitimacy of the police.

\section{The current study}

With contradictory results from the few studies conducted so far, it remains unclear how victims respond to interactions with officers who wear body cameras. Do they feel a greater sense of security because officers are being held to a higher standard of accountability? Or are they likely to feel inhibited by the presence of the camera, realizing that what is captured on film becomes a permanent record that may be used in ways they have no control over by prosecutors, defense attorneys, or local news services?
We worked with a medium-sized east coast police department to design a study that asked crime victims to rate encounters under three conditions: Officer did not wear a body camera; officer wore a body camera and announced to the victim that he or she was being recorded; and officer announced that he or she wore a camera and turned the camera off if the victim objected to being recorded. Measures included victim comfort level in talking to officer, victim perceptions of treatment by the officer, and victim satisfaction with the encounter.

\section{Research Methods}

\section{Experimental treatments}

We planned to implement the field test with three conditions. In the first condition (Standard Protocol) officers followed standard departmental protocol on body camera use. That is, they would have cameras turned on when approaching victims and witnesses. Officers would activate their BWC when dispatched to a call and notify victims and witnesses that they were being recorded when practical. Officers were not required to initiate or cease recording at the request of the citizen. In the second condition (Alternate Protocol) officers were instructed to notify victims and witnesses that they were being recorded, and turn cameras off if the citizen objected. Officers in each of the first two conditions were trained on their particular protocol when using the cameras. In the final condition, officers were not be issued cameras (control condition).

\section{Assignment to treatments}

It was not feasible to randomize by patrol officer because multiple officers from a squad typically respond to calls for service. Inevitably, officers from different conditions would be on the scene together, muddying the experimental assignments. So, our best option was to randomize by geographical area. Fourteen squads participated in the field test. The study took two matched squads each containing ten officers from each of the police department's seven police districts and randomly assigned one member of each pair to a body camera condition and the other to a no camera control. Each squad of the matched pair patrols the same geographic territory over shifts that vary weekly so that each squad covers all shifts eventually (more on this below).

As stated above, the prevailing departmental policy for the seven squads with body cameras was to have cameras running unannounced when interviewing victims and witnesses. For three randomly selected squads of the seven with cameras, officers were retrained under experimental directions stating that officers must announce to victims and witnesses that they were being recorded and to turn off the camera if requested.

The design is a quasi-randomization since we did not actually randomize the squad assigned to any shift or day (that would not be possible for a department to do). But rather, we think that the sequencing of these units is essentially random. The choice of squad to be assigned as experimental and control was random, and then we "seeded" or selected their first shift (that determines the rotations) randomly. Since the squads are matched and the shift rotations are systematic and symmetrical, we believe that there is a good argument to be made that the design minimized any potential treatment biases.

\section{Measures}

The outcome measure that we used to assess the impact of the three experimental treatments was victim ratings of the interaction 
with the officer based on survey data. We patterned the survey items after a set of contact surveys used in earlier work on developing standardized police performance measures [39]. Two of the questions are drawn from that survey. The others are, of necessity, developed specially for this work to elicit victim feelings about comfort about being recorded.

Items included:

- I felt comfortable talking to the officer

- I felt able to talk freely about the incident

- I was able to relate my story in detail

- I felt the officer treated me with respect

- I am satisfied with the way the officer handled the situation

- Do you know if the officer was recording you during this encounter

Response options for each of the first five items ranged from strongly agree to strongly disagree on a five-point scale. Response options for the final item included "yes", "no", and "not sure."

\section{Observations}

A structured observation form was created for research assistants to complete during ride-alongs with patrol officers. The form recorded the use of body cameras at all service calls; officer announcements about recording when approaching citizens; and victim and witness demeanor during police interactions. The observations would form an additional window into officer-citizen interactions and what officers thought of wearing body cameras.

\section{Procedures}

In the late summer of 2018, the department began to send research staff weekly activity logs of officers in the squads participating in the experiment. The weekly list included each officer's experimental group, name, offense type, victim name, victim phone number, victim age, and victim gender. The lists were received, they were then processed and became the basis for a dual survey methodology. First, citizens were invited to answer the survey via text message (SMS) using Qualtrics to distribute the survey. Then unresponsive participants were contacted by phone by interviewers from a professional survey organization.

\section{Victim surveys}

Victims included in the sampling frame were those who had the police come in response to a crime complaint during the previous week. An SMS survey was sent to mobile phones during evening hours twice, with 48-hour spacing. Victims not responding to the SMS survey request were then contacted by telephone by staff of the survey center. Survey center staff made up to three attempts to reach victims, with calls spread out between weekdays, weekday evenings, and Saturdays.

\section{Observations}

Beginning in August 2018, we sent two research assistants to conduct 32 ride-alongs with the department, throughout the department's seven districts. Prior to the ride alongs, each research assistant completed two-hour training on observer-participant studies and note taking. Training included how to build rapport with officers, appropriate times to ask questions, and how to write brief notes for longer narratives. All ride-alongs were conducted during the department's second shift (between 3:30pm and 11:30pm) when the department receives the most calls for service. The observations were limited to the squads that had been issued body cameras. The observations resulted in records of 321 police-citizen interactions over 32 shifts.

\section{Results}

\section{Response rates}

Over the intake period, the SMS survey achieved a $13 \%$ response rate $(n=155)$. Forty-eight hours after the second SMS invitation was sent, the responsive participants were removed from the weekly list. Those remaining on the list and those with land lines listed on the police log were then contacted by survey center interviewers by phone to answer the same questions as the SMS survey. The survey center attempts resulted in a $28 \%$ response rate $(n=301)$. Combining the two sets of respondents (SMS and phone), the survey produced an unexpectedly high overall response rate of $37 \%$ (451 completes out of 1,237 victim attempts).

\section{Victim rating of the interaction}

(Table 1) displays the means and standard deviations for victim ratings of their interaction with a patrol officer. Ratings on each of the items for all of the groups were quite high, averaging over 4 on a scale of 1-5. While the highest ratings on each item were in the Alternate Protocol, none of the differences between means approached statistical significance when comparing either the three conditions or when comparing the combined body camera conditions with the control condition.

\begin{tabular}{|c|c|c|c|c|c|}
\hline Protocol & $\begin{array}{c}\text { Comfortable } \\
\text { talking to offi- } \\
\text { cer? M (SD) }\end{array}$ & $\begin{array}{c}\text { Able to } \\
\text { talk freely? }\end{array}$ & $\begin{array}{c}\text { Able to } \\
\text { relate your } \\
\text { story? }\end{array}$ & $\begin{array}{c}\text { Treated } \\
\text { with } \\
\text { respect? }\end{array}$ & $\begin{array}{c}\text { Satisfied } \\
\text { with en- } \\
\text { counter? }\end{array}$ \\
\hline Control & $4.47(1.14)$ & $4.43(1.18)$ & $4.25(1.31)$ & $4.46(1.14)$ & $3.99(1.46)$ \\
\hline (N=182) & & & & & \\
\hline $\begin{array}{c}\text { Standard } \\
\text { Protocol }\end{array}$ & $4.27(1.31)$ & $4.41(1.23)$ & $4.40(1.23)$ & $4.35(1.24)$ & $4.07(1.40)$ \\
\hline (N=131) & & & & & $4.22(1.33)$ \\
\hline $\begin{array}{c}\text { Alternate } \\
\text { Protocol }\end{array}$ & $4.52(1.07)$ & $4.48(1.16)$ & $4.47(1.04)$ & $4.52(1.06)$ & \\
\hline (N=132) & & & & & \\
\hline
\end{tabular}

Table 1: Means and standard deviations of victim ratings of interactions with patrol officers by experimental treatment.

To investigate possible differences between the experimental conditions, we attempted to combine the victim ratings on the five individual items into a composite measure. In order to determine whether it was reasonable to assume an underlying construct and combine the items, we calculated Cronbach's alpha, a measure of internal consistency. We obtained an alpha of 0.92 (possible values of alpha range from 0 to 1 ) indicating that the items were strongly inter correlated. We therefore created a composite rating by computing an average score for the five items. Average ratings for the three observed groups are displayed in (Figure 1) below. As with the individual items, inter-group differences were slight. Again, on a scale of 1 to 5, composite ratings for each of the three groups were high, running between 4.3 and 4.5. 


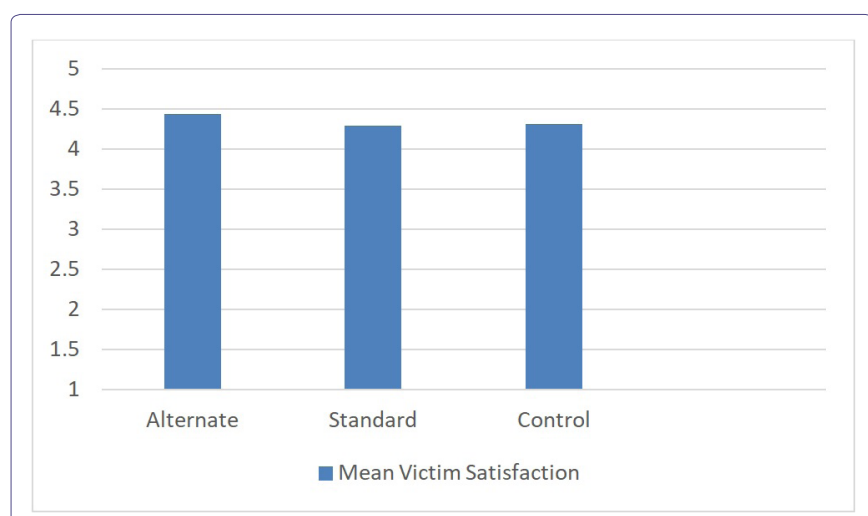

Figure 1: Composite victim ratings of interaction with police officer.

We ran an ANOVA test on the composite victim ratings, one version comparing the three observed conditions (Table 2) and the other comparing the Standard Protocol and Alternate Protocol combined with the control condition (Table 3). Both tests included victim gender, type of crime (Part I offense versus others), and survey mode (SMS versus phone) as factors and age as a covariate.

\begin{tabular}{|c|c|c|}
\hline & df & F \\
\hline Group & 2 & 0.461 \\
\hline Mode & 1 & $4.274 *$ \\
\hline Gender & 1 & 0.099 \\
\hline Age & 1 & 0.75 \\
\hline Offense Type & 1 & 2.427 \\
\hline
\end{tabular}

Table 2: Between-group analysis of the three experimental groups.

Notes: ${ }^{*} \mathrm{p}<0.05 ; * * \mathrm{p}<0.001$. For Group, the control, alternate, and standard are analyzed. Offense Type is dichotomized as Part 1 offense or not.

\begin{tabular}{|c|c|c|}
\hline & df & F \\
\hline Group & 1 & 0.174 \\
\hline Mode & 1 & $4.443 *$ \\
\hline Gender & 1 & 0.133 \\
\hline Age & 1 & 0.06 \\
\hline Offense Type & 1 & 2.353 \\
\hline
\end{tabular}

Table 3: Between-group analysis of the combined body camera groups and control group.

Notes: ${ }^{*} \mathrm{p}<0.05 ;{ }^{* *} \mathrm{p}<0.001$. For Group, only the control and standard are analysed. Offense Type is dichotomized as Part 1 offense or not.

In neither analysis did the treatment variable approach statistical significance. The only significant effect in either analysis was survey mode: Those victims who completed a survey via SMS had higher ratings than victims who completed surveys by phone. It was also true that those persons who completed the survey via SMS were significantly older than victims who completed surveys on the phone (mean age for SMS was 46 years compared to 41 years for phone; $\mathrm{F}[1,418]=10.96, \mathrm{p}<.01)$. This came as a surprise: We had expected that the SMS mode would capture younger victims. The final item in the victim survey asked whether victims were aware of that the officer they interacted with was wearing a body camera. Just $10 \%$ of the Standard Protocol group and 9\% of the Alternate Protocol responded affirmatively: The remainder either did not notice or believed the officer was not wearing a body camera. Surprisingly, those percentages were identical to the percentage of victims in the control group (9\%) who (mistakenly) believed that the officer they interacted with was wearing a camera. Essentially, this says that victims did not notice the body cameras. We did one further analysis to determine whether the small percentage of victims who noticed that officers were wearing cameras rated the encounter differently than victims who were unaware of the body camera. We compared ratings of the encounter between victims who believed that officers were wearing body cameras and those who did not think the officer wore a camera or were unsure. We found no difference in ratings of the encounter between these two groups $(\mathrm{t}[412]=0.59$, n.s. $)$.

\section{Observational data on victim reactions to being recorded}

The finding from the victim survey that the body cameras went unnoticed tallies with what our researchers conducting ride-alongs observed. According to our observers, in $98 \%$ of the interactions in the Alternate Protocol condition, victims did not visibly react to being recorded, even when being told that they were being filmed. In the Standard Protocol condition, none of the victims visibly reacted to the body camera and observers believed that the vast majority of victims were not aware they were being recorded. No victims were observed objecting to the use of the body camera.

\section{Conclusion}

We designed this study to determine whether different protocols for how police officers approach victims while wearing body cameras affect the willingness of victims to provide information on reported incidents. We compared a condition in which (1) officers simply recorded interviews with victims and witnesses against (2) a condition in which officers were instructed to announce to citizens that they were being recorded and would cease recording if requested to do so by the citizen and (3) a condition in which officers did not wear body cameras. We did not find differences between any of these conditions in victim ratings of the interaction. Our results are largely consistent with both the PERF (2017) and Urban Institute studies. Congruent with our work, the PERF study reported no difference on satisfaction or procedural justice citizen survey measures between conditions in which officers did versus did not wear a body camera. In the Urban Institute study, the conditions were no body camera, body camera, and body camera plus procedural justice script. The headline finding presented in that paper was that civilians in the camera plus procedural justice script group rated the interaction more highly than civilians in the no camera group. The report also stated that there was a positive effect of the camera only treatment relative to the no camera control group, but the effects were small. The one study that is a significant outlier was the recent quasi-experiment conducted by in Turkey. These authors found that just the presence of body cameras with an announcement that citizens in traffic stops were being recorded had a strong effect on citizen perceptions of procedural justice and police legitimacy when compared to a condition where officers did not wear cameras.

Our field test was based on the assumption that people would notice and react to police body cameras. That assumption proved to be largely wrong. Only a small minority of victims surveyed believed that the officer they spoke with was wearing a body camera, and the percentage that did notice was consistent across treatments: That is, victims in both of the body camera conditions were no more likely 
than victims in the no camera control condition to report that the officer they spoke with was wearing a body camera. This finding was corroborated by our extensive observational data as well. According to our observers, in $98 \%$ of the interactions where officers wore cameras, victims did not visibly react to being recorded, even when being told that they were being filmed. No victim objected to being recorded in the 321 incidents that researchers observed. The finding that a large majority of victims was unaware of being recorded confirms a similar finding from the Urban Institute study.

Further, our survey data analysis determined that, even when victims were aware of officers wearing body cameras, there was no change in how they rated their interactions with the officer. Similarly, [40] also found very few citizens were aware they were being recorded. In contrast to the present study, however, they reported that citizens who were aware of being recorded rated the encounter more favourably and procedurally just. Thus, the major finding in our study is that most victims do not notice body cameras and when they do notice, they do not object to being recorded. Moreover, those victims who did believe that the officer wore a camera did not rate the encounter higher than victims who did not believe or were not sure that the officer had a camera. Our findings support a body camera policy which does not require that victims give consent to having body cameras on. Rather, officers should be given a degree of discretion to discontinue recording in sensitive situations, or situations in which victims strongly object, as long as they record the reason for deactivating the recording. Our results suggest that officers will have to use such discretion only infrequently. Conversations that our observers had with officers during the course of ride-alongs suggest that it may take time for officers to become comfortable with wearing cameras. Officers expressed practical concerns about camera operation and data uploads, but also some concern that cameras invaded their privacy and ability to exercise reasonable discretion without being second guessed later by supervisors reviewing recordings. Still, officers appreciated that the cameras could have a protective effect in the event that a citizen complaint was filed against them. There was a consensus that body cameras have a "civilizing" effect on both citizen and officer behavior. However, there was disagreement whether the presence of the camera was a helpful reminder to officers to be courteous in their interactions with citizens or a restriction on using "street language" in attempting to control a disrespectful suspect.

Finally, the study broke new methodological ground in using surveys to measure citizen evaluations with police encounters. Using a combination of SMS and phone modalities to conduct the surveys with victims, we achieved an unexpectedly high $37 \%$ response rate and reduced costs substantially over what would have been spent had we used only phone modality. This response rate was double what was achieved in either the PERF (2017) or Urban Institute studies using telephone modality alone. Surprisingly, the SMS modality pulled in a higher percentage of older respondents compared to phone. SMS is a very inexpensive way to gather feedback: Our costs were $\$ 0.62$ per completed survey, compared to $\$ 48$ per completed survey by phone. It is concerning those victim ratings of the interaction varied significantly between the two modalities even after controlling for gender, type of crime and age. Nonetheless, we plan to use the same mixed mode method in future work, and we will be interested to gather more data about which subpopulations are best reached with the two modalities.

\section{References}

1. Stanley (2013) Police body-mounted cameras: With right policies in place, a win for all.

2. Johnson K (2014) Today's police put on a gun and a camera. The New York Times.

3. Repard P (2014) Privacy an issue with police body cameras, The San Diego Union-Tribune.

4. Harris D (2010) Picture this: Body worn video devices ("Head cams") as tools for ensuring fourth amendment compliance by police 13: 1-19.

5. White MD (2014) Police officer body-worn cameras: Assessing the evidence. Washington, DC: Office of Community Oriented Policing Services.

6. Crow MS, Snyder JA, Crinchlow VJ, Smykla JO (2017) Community perceptions of police BWCs: The impact of views of fairness, fear, performance, and privacy. Criminal Justice and Behavior 44: 589-610.

7. Ariel B, Farrar W, Sutherland A (2014) The effect of police body-worn cameras on use of force and citizens' complaints against the police: A randomized controlled trial. Journal of Quantitative Criminology 31: 509-535.

8. McCluskey JD, Uchida CD, Solomon SE, Wooditch, A, Connor C, et al. (2017) Assessing the effects of body-worn cameras on procedural justice in the Los Angeles Police Department. Criminology 57: 208-236.

9. Lum C, Stoltz M, Koper CS, Scherer AJ (2019) Research on body-worn cameras: What we know, what we need to know. Criminology \& Public Policy 18: 1-26.

10. Police Executive Research Forum (2017) Citizen Perceptions of BodyWorn Cameras: A Randomized Controlled Trial, Washington, DC.

11. Yokum D, Ravishankar A, Coppock A (2019) A randomized control trial evaluating the effects of police body-worn cameras. Proceedings of the National Academy of Sciences 116: 10329-10332.

12. La Vigne NG, Lowry SS, Markman JA, Dwyer AM (2011) Evaluating the Use of Public Surveillance Cameras for Crime Control and Prevention. Final Technical Report Washington, DC: The Urban Institute Pg no: 1-131.

13. Andrew F (2011) ODS Consulting, Body worn video projects in Paisley and Aberdeen, self-evaluation.

14. White MD, Gaub JE, Malm A, Padilla KE (2019) Implicate or exonerate: The impact of police body-worn cameras on the adjudication of drug and alcohol cases. Policing.

15. Goodall M (2007) Guidance for the police use of body-worn video devices. Police and crime standards directorate Pg no: 1-113.

16. Weiner R (2013) Police body cameras spur privacy debate, Washington.

17. Wallace D, White MD, Gaub JE, Todak N (2018) Body-worn cameras as a potential source of de-policing: Testing for camera-induced passivity. Criminology 56: 481-509.

18. OMara M (2014). Why police body cameras would work. CNN.

19. Alexander R (2014) Police body camera pilot ends in Spokane; review next. The Seattle times.

20. Victoria Police Department. (2010) Proof of concept study: Body worn video and in vehicle Video, Victoria British Columbia, Canada.

21. Peterson BE, Yu L, La Vigne N, Lawrence DS (2018) The Milwaukee police department's body-worn camera program; Evaluation findings and key takeaways. Washington, DC: Urban Institute.

22. Ready J, Young J (2014) Three myths about police body cams Slate.

23. Lawrence DS, Peterson B (forthcoming). How do body-worn cameras affect the amount and makeup of police-initiated activities? A randomized controlled trial in Milwaukee,Wisconsin. Journal of Experimental Criminology Pg no: 1-23. 
24. Police Executive Research Forum. (2014) Implementing a Body-Worn Camera Program: Recommendations and Lessons Learned, Washington, DC: COPS.

25. Lum C, Koper CS, Merola LM, Scherer A, Reioux A (2015) Existing and Ongoing Body Worn Camera Research: Knowledge gaps and opportunities. Center for Evidence-Based Crime Policy,George Mason University Pg no: $1-30$

26. Braga AA, Coldren JR, Sousa W, Rodriguez D, Alper O, et al. (2017) The benefits of body-worn cameras: New findings from a randomized controlled trial at the Las Vegas Metropolitan Police Department. CNA Analysis \& Solutions.

27. Capps L (2015) Police body-worn cameras: An overview. The Police Chief 82: $52-54$.

28. Tibbetts S (2015) Police Body Cameras in Domestic and Sexual Assault Investigations: Considerations and Unanswered Questions. Battered Women's Justice Project.

29. Friedersdorf C (2015) Who should see recordings from police bodycams? Atlantic.

30. Strand R (2012) Investigating sexual assault: How the Army is using training to change the Culture, Soldier.

31. Todak N, Gaub JE, White MD (2018) The importance of external stakeholders for police body-worn camera diffusion. Policing 41: 448-464.
32. Volz D (2014) Police body cameras are already facing police skeptics.

33. Brunt J (2014) Washington chief weighs pros and cons of body cameras. The Spokesman-Review.

34. ManTech (2012) A primer on body-worn cameras for law enforcement.

35. IACP (2014) Body worn cameras model policy.

36. Rowe M, Pearson G, Turner E (2018) Body-worn cameras and the law of unintended consequences: Some questions arising from emergent practices. Policing 12: 83-90.

37. McClure D, Vigne NL, Lynch M, Golian L, Lawrence D, et al. (2017) How body cameras affect community members perceptions of police. Washington, DC: Justice Policy Center, Urban Institute, Pg no: 1-12.

38. Demir M, Apel R, Braga AA, Brunson RK, Ariel B, et al. (2018) Body Worn Cameras, Procedural Justice, and Police Legitimacy: A Controlled Experimental Evaluation of Traffic Stops. Justice Quarterly 37: 1-32.

39. Davis RC, Ortiz C, Euler S, Kuykendall L (2015) Revisiting "Measuring What Matters:" Developing a suite of standardized performance measures of policing. Police Quarterly $18: 469-495$.

40. White MD, Todak N, Gaub JE (2017) Assessing citizen perceptions of body-worn cameras after encounters with police. Policing 40: 689-703. 


\section{H}

Advances In Industrial Biotechnology | ISSN: 2639-5665

Advances In Microbiology Research | ISSN: 2689-694X

Archives Of Surgery And Surgical Education | ISSN: 2689-3126

Archives Of Urology

Archives Of Zoological Studies | ISSN: 2640-7779

Current Trends Medical And Biological Engineering

International Journal Of Case Reports And Therapeutic Studies | ISSN: 2689-310X

Journal Of Addiction \& Addictive Disorders | ISSN: 2578-7276

Journal Of Agronomy \& Agricultural Science | ISSN: 2689-8292

Journal Of AIDS Clinical Research \& STDs | ISSN: 2572-7370

Journal Of Alcoholism Drug Abuse \& Substance Dependence | ISSN: 2572-9594

Journal Of Allergy Disorders \& Therapy | ISSN: 2470-749X

Journal Of Alternative Complementary \& Integrative Medicine | ISSN: 2470-7562

Journal Of Alzheimers \& Neurodegenerative Diseases | ISSN: 2572-9608

Journal Of Anesthesia \& Clinical Care | ISSN: 2378-8879

Journal Of Angiology \& Vascular Surgery | ISSN: 2572-7397

Journal Of Animal Research \& Veterinary Science | ISSN: 2639-375

Journal Of Aquaculture \& Fisheries | ISSN: 2576-5523

Journal Of Atmospheric \& Earth Sciences | ISSN: 2689-8780

Journal Of Biotech Research \& Biochemistry

Journal Of Brain \& Neuroscience Research

Journal Of Cancer Biology \& Treatment | ISSN: 2470-7546

Journal Of Cardiology Study \& Research | ISSN: 2640-768X

Journal Of Cell Biology \& Cell Metabolism | ISSN: 2381-1943

Journal Of Clinical Dermatology \& Therapy | ISSN: 2378-8771

Journal Of Clinical Immunology \& Immunotherapy | ISSN: 2378-8844

Journal Of Clinical Studies \& Medical Case Reports | ISSN: 2378-880

Journal Of Community Medicine \& Public Health Care | ISSN: 2381-1978

Journal Of Cytology \& Tissue Biology | ISSN: 2378-9107

Journal Of Dairy Research \& Technology | ISSN: 2688-9315

Journal Of Dentistry Oral Health \& Cosmesis | ISSN: 2473-6783

Journal Of Diabetes \& Metabolic Disorders | ISSN: 2381-201X

Journal Of Emergency Medicine Trauma \& Surgical Care | ISSN: 2378-8798

Journal Of Environmental Science Current Research | ISSN: 2643-5020

Journal Of Food Science \& Nutrition | ISSN: 2470-1076

Journal Of Forensic Legal \& Investigative Sciences | ISSN: 2473-733X

Journal Of Gastroenterology \& Hepatology Research | ISSN: 2574-2566
Journal Of Genetics \& Genomic Sciences | ISSN: 2574-2485

Journal Of Gerontology \& Geriatric Medicine | ISSN: 2381-8662

Journal Of Hematology Blood Transfusion \& Disorders | ISSN: 2572-2999

Journal Of Hospice \& Palliative Medical Care

Journal Of Human Endocrinology | ISSN: 2572-9640

Journal Of Infectious \& Non Infectious Diseases | ISSN: 2381-8654

Journal Of Internal Medicine \& Primary Healthcare | ISSN: 2574-2493

Journal Of Light \& Laser Current Trends

Journal Of Medicine Study \& Research | ISSN: 2639-5657

Journal Of Modern Chemical Sciences

Journal Of Nanotechnology Nanomedicine \& Nanobiotechnology | ISSN: 2381-2044

Journal Of Neonatology \& Clinical Pediatrics | ISSN: 2378-878X

Journal Of Nephrology \& Renal Therapy | ISSN: 2473-7313

Journal Of Non Invasive Vascular Investigation | ISSN: 2572-7400

Journal Of Nuclear Medicine Radiology \& Radiation Therapy | ISSN: 2572-7419

Journal Of Obesity \& Weight Loss | ISSN: 2473-7372

Journal Of Ophthalmology \& Clinical Research | ISSN: 2378-8887

Journal Of Orthopedic Research \& Physiotherapy | ISSN: 2381-2052

Journal Of Otolaryngology Head \& Neck Surgery | ISSN: 2573-010X

Journal Of Pathology Clinical \& Medical Research

Journal Of Pharmacology Pharmaceutics \& Pharmacovigilance | ISSN: 2639-5649

Journal Of Physical Medicine Rehabilitation \& Disabilities | ISSN: 2381-8670

Journal Of Plant Science Current Research | ISSN: 2639-3743

Journal Of Practical \& Professional Nursing | ISSN: 2639-568

Journal Of Protein Research \& Bioinformatics

Journal Of Psychiatry Depression \& Anxiety | ISSN: 2573-0150

Journal Of Pulmonary Medicine \& Respiratory Research | ISSN: 2573-0177

Journal Of Reproductive Medicine Gynaecology \& Obstetrics | ISSN: 2574-2574

Journal Of Stem Cells Research Development \& Therapy | ISSN: 2381-2060

Journal Of Surgery Current Trends \& Innovations | ISSN: 2578-7284

Journal Of Toxicology Current Research | ISSN: 2639-3735

Journal Of Translational Science And Research

Journal Of Vaccines Research \& Vaccination | ISSN: 2573-0193

Journal Of Virology \& Antivirals

Sports Medicine And Injury Care Journal | ISSN: 2689-8829

Trends In Anatomy \& Physiology | ISSN: 2640-7752

Submit Your Manuscript: https://www.heraldopenaccess.us/submit-manuscript 